\title{
The Colorado Asthma Toolkit Program: A Practice Coaching Intervention from the High Plains Research Network
}

\author{
Bruce G. Bender, PhD, Perry Dickinson, MD, Allison Rankin, MPH, \\ Frederick S. Wamboldt, MD, Linda Zittleman, MSPH, and John M. Westfall, MD, MPH
}

Introduction: Asthma is often under-diagnosed and under-treated in primary care. The Colorado Asthma Toolkit Program was initiated to establish a method for improving asthma care by providing to primary care practices coaching, training, and support for (1) evidence-based asthma diagnosis and treatment, and (2) education and activation of patients toward effective self-management of their illness.

Methods: A collaborative program was initiated involving 2 academic medical institutions and the High Plains Research Network, a primary care practice-based research network in eastern Colorado. Focus groups were conducted with rural Colorado patients and health care clinicians to assess need and determine the most effective intervention strategies. Two intertwined training programs, or "toolkits," were subsequently developed, one each for health care clinicians and patients. Clinicians received 3 coaching sessions conducted by 2 nurses in the practice that included training in guideline-based methods for evaluation and treatment of asthma, coaching to assist practices in implementing these methods, and training in communication techniques to promote asthma self-management. Practices were also given a spirometer and trained in its use and interpretation. Patient self-management toolkits were provided to clinicians, who were trained to use the materials to educate patients and increase treatment adherence. Evaluations were based on practice interviews 1 to 3 months after coaching.

Results: Coaching occurred in 57 of the 58 primary care offices in eastern rural and semirural Colorado. Practices reported changes in their asthma management behaviors: (1) $40.4 \%$ of practices increased their use of inhaled corticosteroids, with the median percent of patients taking inhaled corticosteroids rising from $25 \%$ to $50 \%$; (2) $53.2 \%$ of practices increased their use of asthma action plans, with the median percent of patients with action plans rising from $0 \%$ to $20 \%$; and (3) $78.7 \%$ of practices initiated or increased their use of spirometry, resulting in a rise in median use from $0 \%$ to $30 \%$.

Conclusion: The Colorado Asthma Toolkit Program successfully disseminated asthma care training into a majority of area rural health care practices. Acceptance by practices was attributable to flexible, in-office coaching and provision of spirometry. Significant shifts seen in asthma-management practices are likely to reduce hospitalizations and emergency department visits. (J Am Board Fam Med 2011;24:240-248.)

Keywords: Asthma, Evidence-based Guidelines, Provider Training

Asthma is inadequately controlled in a substantial number of patients. ${ }^{1,2}$ In a survey of 60,000 patients

This article was externally peer reviewed.

Submitted 21 July 2010; revised 15 November 2010; accepted 30 November 2010.

From the Departments of Pediatrics (BGB) and Medicine (AR, FSW), National Jewish Health, Denver, CO; and the Department of Family Medicine, University of Colorado Denver, Aurora, CO (PD, LZ, JMW).

Funding: Funding for this project was provided through the Cancer, Cardiovascular, and Pulmonary Disease grants program administered by the Colorado Department of Public Health and Environment (07-FLA-00595). with asthma, 74\% reported symptoms indicating poor control and $40 \%$ reported not using controller therapy. ${ }^{2}$ The underlying causes are related both to clinicians and to patients. A survey of primary care physicians indicated that only $54 \%$ of pediatricians and $51 \%$ of family physicians followed evidence-based guidelines from the National

Conflict of interest: none declared.

Corresponding author: Bruce G. Bender, $\mathrm{PhD}$, National Jewish Health, 1400 Jackson Street, Denver, CO 80112, (E-mail: benderb@njhealth.org). 
Heart, Lung and Blood Institute (NHLBI) for prescribing daily controller medication. ${ }^{3}$ Half of patients who receive an asthma diagnosis have never had an evaluation with spirometry, a key assessment in the NHLBI guidelines. ${ }^{4}$ Even when daily controller medications are prescribed, fewer than half of patients adhere to their treatment regimens. ${ }^{5,6}$ Hence, interventions to improve asthma control must address changes in both clinician and patient behavior. Programs to improve clinician adherence to asthma guidelines have proven somewhat successful but have focused primarily on urban health care centers. ${ }^{7-9}$ Such programs also have tended to rely more on centralized continuing medical education efforts rather than going to primary care practices for a more in-depth, multilevel intervention to incorporate improvements in the practice. Onsite practice coaching or facilitation has been increasingly used as a method for assisting practices in implementing practice improvements, with the extent and intensity of coaching varying according to the complexity of the targeted changes and improvements. ${ }^{10-14}$ The presence of a practice coach can assist in tailoring an intervention to an individual practice situation, improving the incorporation of the intervention into the daily routine of the practice system and increasing the sustainability of change. ${ }^{15}$

Patients with asthma who live in rural or smalltown areas are less likely to receive current evidence-based asthma care ${ }^{16}$ and are more likely to require an emergency department visit or hospitalization for their asthma than those in urban areas. In Colorado, rural areas also include a large number of low-income and medically underserved patients, a group at increased risk for asthma morbidity and mortality. ${ }^{17,18}$ For these reasons, the Colorado Asthma Toolkit Program was initiated to provide in-office coaching, training, and support for primary care clinicians and practices in rural and semirural areas of eastern Colorado. The program includes emphasis on providing effective selfmanagement training for patients, an essential component of the NHLBI guidelines. ${ }^{4}$

\section{Methods}

The Colorado Asthma Toolkit Program was a collaboration between National Jewish Health, the University of Colorado School of Medicine, and the High Plains Research Network (HPRN), a practice-based research network in eastern Colorado. Funding was provided through the Cancer, Cardiovascular, and Pulmonary Disease grants program administered by the Colorado Department of Public Health and Environment. The institutional review boards of the collaborating institutions approved the program. The program was introduced in 15 counties that include 58 primary care practices in the 30,000 square mile high plains area of Colorado, east of the Front Range cities of Fort Collins, Greeley, Boulder, Denver, Colorado Springs, and Pueblo. Most of the 15 counties, which include Baca, Bent, Cheyenne, Crowley, Elbert, Kiowa, Kit Carson, Lincoln, Logan, Morgan, Otero, Phillips, Sedgwick, Washington, and Yuma, have populations of fewer than 10,000 , and 5 have populations of fewer than 5000. Most of the clinics care for underserved patients and are classified as frontier clinics because the nearest tertiary care center is more than 50 miles away. All are included in the HPRN.

\section{Program Development}

Development of the Program Occurred in the First Year Community engagement was an essential first step toward assuring the success of the Colorado Asthma Toolkit Program. Four patient focus groups and 2 clinician town-hall meetings were conducted in the HPRN to assess patient and clinician needs regarding asthma care training. Patient focus groups were conducted with 36 patients or parents of children with asthma and included discussion of patient experiences with asthma, asthma medication, and health care clinicians. Participants also reviewed drafts of patient education materials and strategies and were invited to give feedback and suggestions. Health care clinician town-hall meetings included 39 clinicians, nurses, and office managers who received an overview of the goals of the Colorado Asthma Toolkit Program and were invited to ask questions and provide suggestions for ways to make the program most helpful to them.

\section{Program Launch}

Patient and clinician feedback was used to shape the final program. The Colorado Asthma Toolkit Program included 2 central components, or "toolkits." The first was aimed at increasing the capacity of primary care practices to assess and manage asthma as directed by current evidence-based guidelines. The second was aimed at helping clini- 
cians to educate and support patients and parents to increase medication adherence and effective selfmanagement. All practices in the HPRN provide care to medically underserved patient populations, including federally qualified community health centers and practices that serve rural, low-income, and/or Spanish-speaking patients.

\section{Clinician/Practice Toolkit}

A central component of this program endorsed in the clinician town-hall meetings was the provision of onsite coaching and support for clinicians, thereby assuring a high rate of participation. Practice clinicians and staff received training in the management of asthma consistent with evidencebased guidelines and in the use and interpretation of spirometry for both acute and long-term assessment of control. Although use of spirometry for asthma diagnosis and management is recommended in the NHLBI guidelines, ${ }^{4}$ most primary care practices did not use or own spirometry equipment. Therefore, each practice was provided with a spirometer designed for use in a primary care practice and that did not require daily recalibration (Figure 1).

Practice coaching occurred during the last 2 years of the program and was conducted by 2 licensed nurses who had extensive previous experience with asthma assessment and treatment. Both coaches resided in the counties where coaching occurred. Each coach attended 5 training days under the supervision of National Jewish faculty. Practice training content was taught to the coaches, asthma educator certification was obtained, and practice sessions were held, during which the coaches practiced lecture and discussion skills. An allergist and senior nurse faculty member from National Jewish Health continued to supervise the coaches as the training program was introduced and periodically attended training sessions to provide additional training support.

The first in-practice coaching visit focused on asthma assessment and management following NHLBI evidence-based guidelines, which emphasize achieving control of asthma symptoms and provide a stepwise approach to treating persistent asthma. ${ }^{4}$ Central to the guidelines-directed approach to asthma is recognition that chronic airway inflammation underlies airflow limitation and that use of daily controller medication, typically an inhaled corticosteroid, is required for patients with persistent asthma. Because patients' perceptions of airflow are highly variable, objective assessment with spirometry is recommended for most patients with asthma. Clinicians also were advised to provide to all patients a written asthma action plan that includes instructions for both daily management and actions to be taken to manage worsening asthma. A detailed summary of the guidelines is available on the NHLBI website. ${ }^{19}$

During the first visit of the Colorado Asthma Toolkit Program, which lasted a full day, training content included (1) a brief overview of the pathogenesis and treatment of asthma, (2) categorization of severity and control, (3) guidelines for prescribing rescue and controller medications, (4) trigger avoidance, (5) guidelines for referral to a specialist, (6) keys to communicating effectively with patients to improve adherence, and (7) case studies. The coach supervised all staff in hands-on practice with spirometry. Coaching also focused on practical ways to incorporate and systematize the use of

Figure 1. Clinician tools, including training manual and spirometer.
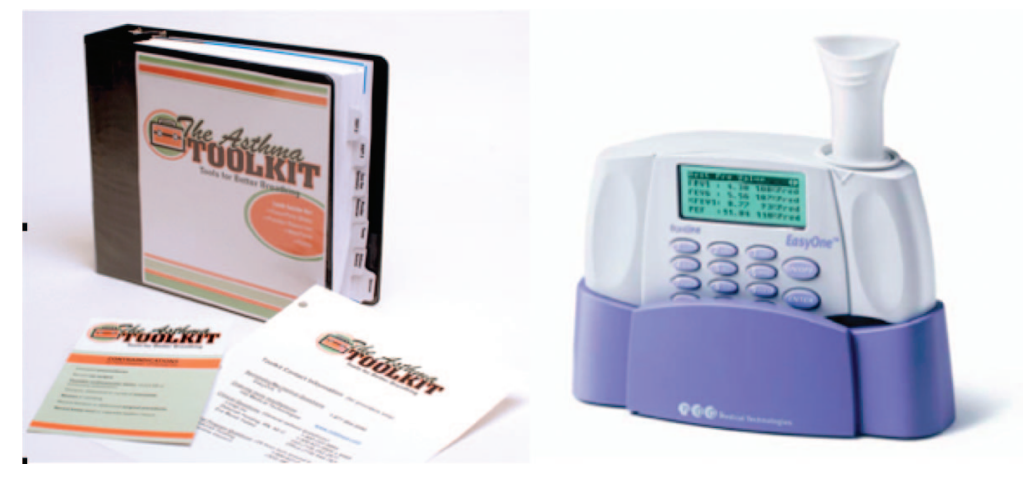
spirometry and other aspects of improved asthma care into the flow of the practice. A supply of patient toolkits (described in detail below) was provided to the practice along with simple forms, in English and Spanish, to enroll patients into the automated telephone education and support program.

The second and third visits, lasting 4 hours each, were used to review and reinforce guidelines-based practice and to review individual cases. Clinicians were encouraged to have example cases ready for discussion. Because spirometric technique is only valid if standardized procedures are maintained, review of spirometry techniques was a key element during these visits. They focused on specific practice needs, answered questions regarding asthma guidelines and management, reinforced and extended spirometry training and skills, and increased clinician understanding of communication strategies to improve patient adherence.

\section{Patient Toolkit}

The patient education and self-management support program was intended to flow from the patient's visit with their health care clinician. Therefore, patient asthma toolkits were given to clinicians, who in turn gave them to the patients during the course of routine office visits (Figure 2). The asthma patient toolkits included a peak flow meter, a clinician checklist that served as a guide for the use of the materials for self-management support, telephone outreach enrollment form, asthma action plan, an "understanding asthma" booklet, and other educational materials assembled into the Colorado Asthma Toolkit Program manual. The manual included National Jewish Health MedFacts, which are information sheets with content about (1) recognizing signs and symptoms of asthma, (2) peak flow monitoring,(3) using an action plan to manage asthma, and (4) recognizing what makes asthma worse. Most of these materials are available costfree at the National Jewish Health website. ${ }^{20}$

Four versions of the toolkit were available for children or adults in either English or Spanish. Practice clinicians were trained to review content with each patient and to remove and complete the asthma action plan from the patient's toolkit. The toolkit also included a visit checklist that allowed the clinician to efficiently document for the patient's medical record that an educational interaction had occurred. The toolkit components were reviewed and modified by the HPRN community advisory council in consultation with the Colorado Asthma Toolkit Program leadership team.

An educational, telephone-based interactive voice response (IVR) program was developed to provide supplemental education and to encourage patient and parent adherence to treatment. IVR uses technology that can place telephone calls to patients and interact by asking the patient to respond on their keypad. It is particularly well-suited to communicate with families located in rural areas because most can be reached by telephone at relatively small cost. Messages, information, and advice to patients were tailored according to the patients' responses and produced in both English and Span-

Figure 2. Patient tools including peak flow meter, educational materials, and Toolkit box.

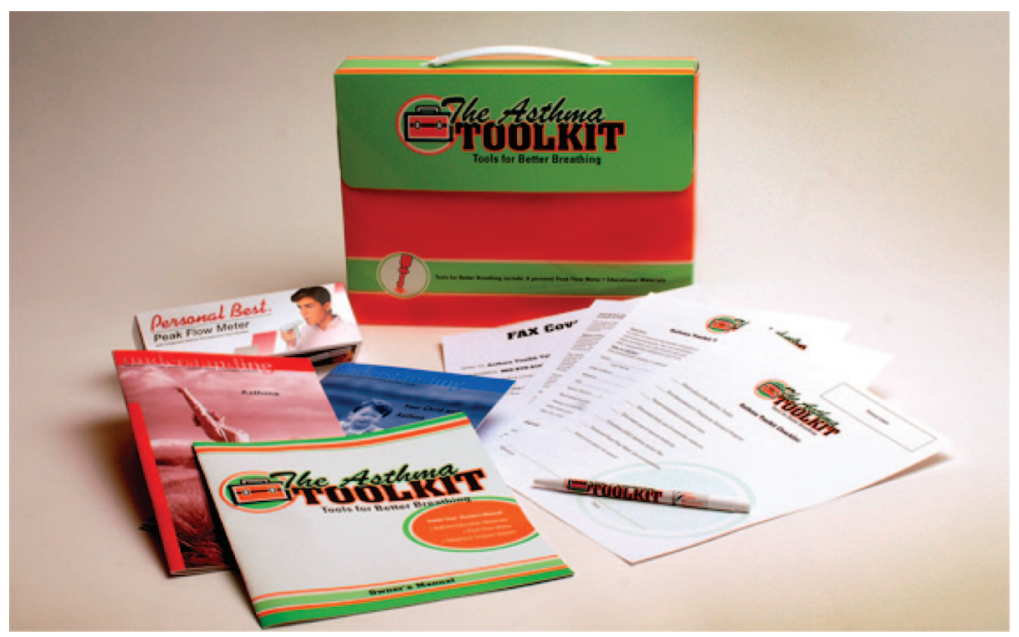


ish. The program inquired about asthma symptoms, delivered core educational messages, and provided advice to patients that could include encouragement to ask questions of asthma care specialists through the National Jewish Health LungLine, refill and regularly use inhaled corticosteroid medication prescriptions, or call Colorado Quitline for smoking cessation assistance. The patient toolkits included IVR program enrollment forms that could be completed by practice staff and faxed to the National Jewish Health coordinating center. Once enrolled, patients received 2 automated IVR telephone calls separated by 1 month, with a possible additional 3 calls if they fell into a "red flag" category that included reports of recent exacerbations, urgent care visits, or failure to fill a prescription. The capacity of the IVR program to increase treatment adherence was demonstrated in a previously published randomized controlled trial. ${ }^{21}$

\section{Data Collection and Analysis}

Evaluation of the Colorado Asthma Toolkit Program focused on its capacity to engage a majority of primary care practices in eastern Colorado and effect changes in asthma management practice behavior. Three specific management behaviors were chosen for evaluation because they are central to the NHLBI evidence-based guidelines and because they are discrete and measurable. These included employment of (1) inhaled corticosteroid (ICS) prescriptions, (2) asthma action plans, and (3) spirometry. All data were collected through a structured interview conducted by research staff, not the practice coaches, 1 to 3 months after completion of all 3 coaching sessions. Both before and after coaching, practice members were asked to estimate the percentage of asthma patients receiving an ICS prescription or action plan. In the case of spirometry, interviewers reviewed with practice members the actual number of spirometry sets recorded in the memory function of their spirometer, which was then divided by the number of asthma patients seen on average each month to estimate the percentage of asthma patients receiving spirometry. Comparisons of the percent of asthma patients receiving spirometry, asthma action plans, and ICS in all practices before and after coaching were completed with a nonparametric Wilcoxon signed-rank tested. To characterize which practices demonstrated a significant shift in the 3 practice behaviors, the proportions of patients in each practice receiving an ICS or asthma action plan were categorized as less than $33 \%, 33 \%$ to $66 \%$, or more than $66 \%$ both before and after receiving the Colorado Asthma Toolkit Program coaching. Proportions in each category were then contrasted using a generalized McNemar's test for comparing paired data.

\section{Results}

Colorado Asthma Toolkit Program coaching occurred in 57 of the 58 (98\%) targeted primary care practices, treating an estimated 15,508 patients with asthma. The cost of training each practice was $\$ 4,194$; this cost included all 3 training visits, the EasyOne spirometer, and 100 patient toolkits. Across practices, 372 clinic team members were trained, including 87 physicians, 130 nurses, 19 physician assistants, 108 medical assistants, 11 practice managers, and 17 office staff. Changes were evaluated for each of the 3 asthma management behaviors. Practices reported particular appreciation of flexible, in-office coaching and provision of spirometry.

\section{ICS Prescriptions}

The proportion of patients with asthma who received an ICS prescription increased from $25 \%$ to $50 \%$ across all practices, representing a significant overall increase in median number of patients receiving ICS (Table 1). An increase in ICS prescriptions for their patients with asthma was reported by $40.4 \%$ of practices, representing a significant up-

Table 1. Percent of Patients Receiving Guidelines-Directed Asthma Care across Practices

\begin{tabular}{lrrrrrrr}
\hline & \multicolumn{2}{c}{ Before Intervention } & & \multicolumn{2}{c}{ After Intervention } \\
\cline { 2 - 3 } & Median & Interquartile Range & & Median & Interquartile Range & $P$ \\
\hline Using inhaled corticosteroid (\%) & 25.0 & 70.0 & & 50.0 & 65.0 & $<.0001$ \\
Patients with an action plan (\%) & 0.0 & 10.0 & & 20.0 & 47.5 & $<.0001$ \\
Patients with Spirometry (\%) & 0.0 & 0.5 & & 40.0 & 37.2 & $<.0001$ \\
\hline
\end{tabular}


ward shift in practice prescribing patterns $(P<$ .004) (Figure 3).

\section{Asthma Action Plans}

Across practices, median action plan use increased from $0 \%$ at baseline to $20 \%$ after coaching (Table 1). Asthma action plan use increased in $53.2 \%$ of practices $(P<.003)$ (Figure 3$)$.

\section{Spirometry}

A large uptake in spirometry use was observed. Across all participating practices, spirometry increased from a median of $0 \%$ to $30 \%$ of patients after coaching (Table 1). Increases in administration were reported in $78.7 \%$ of practices, including the 38 practices that had not previously used spirometry equipment $(P=.0089)$ (Figure 3). During the first year after implementation, the practices had conducted more than 2400 spirometry tests; more than $50 \%$ were abnormal with moderate or severe obstruction.

\section{Discussion}

The Colorado Asthma Toolkit Program was well accepted, reaching 57 of the 58 primary care practices in rural eastern Colorado. This degree of reach, hitting a large percentage of the targeted practices, is striking and speaks to the perceived value of the onsite practice coaching approach. As reported by the practices 1 to 3 months after coaching, significant increases were seen in use of ICS, spirometry, and asthma action plans. If all of the 15,508 people with asthma from the participating practices were seen over a 12 -month period, an estimated 2683 asthma patients would receive an action plan and 1690 would receive new ICS prescriptions. Based on large intervention studies, introduction of ICS to patients with persistent asthma but not using a controller medication reduces asthma hospitalizations and emergency department visits by approximately $50 \% .^{22,23}$ This reduction may be further increased with the use of asthma action plans and patient self-management education. ${ }^{24}$ Based on Colorado hospitalization and emergency department rates, ${ }^{25}$ it is estimated that 107 fewer hospitalizations and 84 fewer emergency department visits in the 15 targeted counties could result annually from changes in asthma management emerging from the Colorado Asthma Toolkit Program. These are estimates that remain to be established in subsequent research. Such studies could utilize the Colorado Asthma Toolkit Program in a controlled study with randomization at the practice level, allowing for follow-up evaluation of patient outcomes including urgent symptom control, oral steroid use, and urgent care visits.

Not all practices reported changes in their approach to asthma management. One-third were already following evidence-based guidelines, prescribing ICS for more than two-thirds of their patients before their coaching, although within this group many were not fully adherent to guidelinesdirected asthma management. Of interest, most of these practices were positive in their feedback about the coaching, reporting greater consistency in their asthma care after coaching. Another onethird of practices continued to prescribe ICS for fewer than 1 in 3 asthma patients after their coaching. Some of these practices expressed reluctance about the coaching, resisting completing all 3 coaching sessions or demonstrating little spirometry use. This resistance occurred despite attempts to bring flexibility to the coaching schedule in each practice, and this underscores the importance of negotiating a coaching plan that is adapted to the practice organization and preferences. A full onethird of practices demonstrated an increased adoption of the 3 asthma management target behaviors. Including those practices already using ICS, action plans, and spirometry, two-thirds of all practices were engaged in these evidence guidelines behaviors after the Colorado Asthma Toolkit Program.

Other programs have provided asthma management training for primary care clinicians, although most have focused on clinicians and patients living in urban settings. One of the largest such programs recruited 74 pediatricians in New York City and Ann Arbor, MI, who subsequently were assigned to a training or control condition. Physicians in the training condition participated in an interactive seminar that included training in evidence-based asthma care and communication skills. The intervention resulted in significant decreases in emergency department and hospital utilization compared with controls among a population of low-income patients. Notably, those physicians trained to manage asthma while communicating more effectively reported no increase in time spent with patients relative to physicians in the control group. ${ }^{26}$ Another large study adopted an approach closer to that of 
Figure 3. Practice uptake of inhaled corticosteroids, asthma action plans, and spirometry.
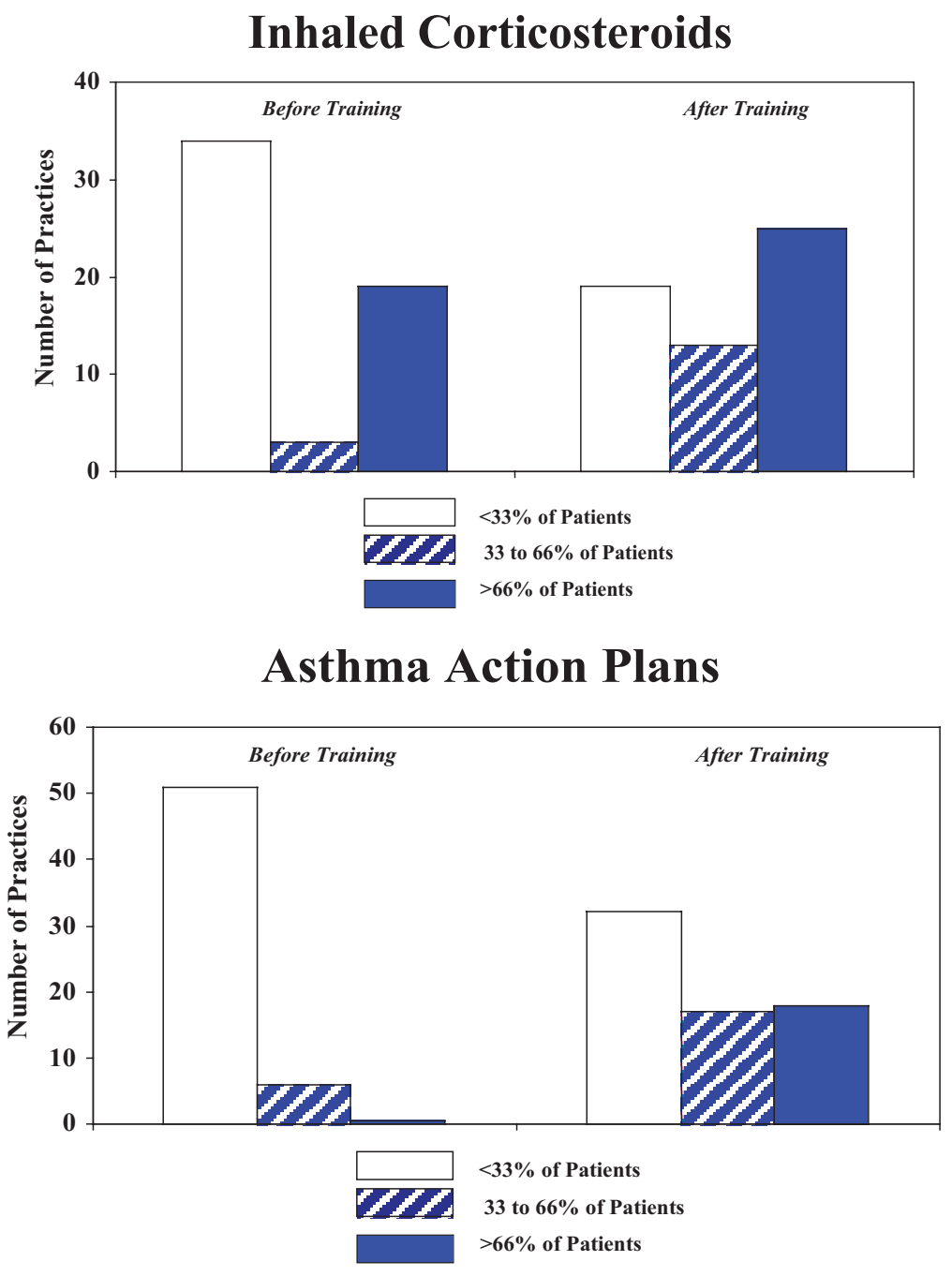

\section{Spirometry}

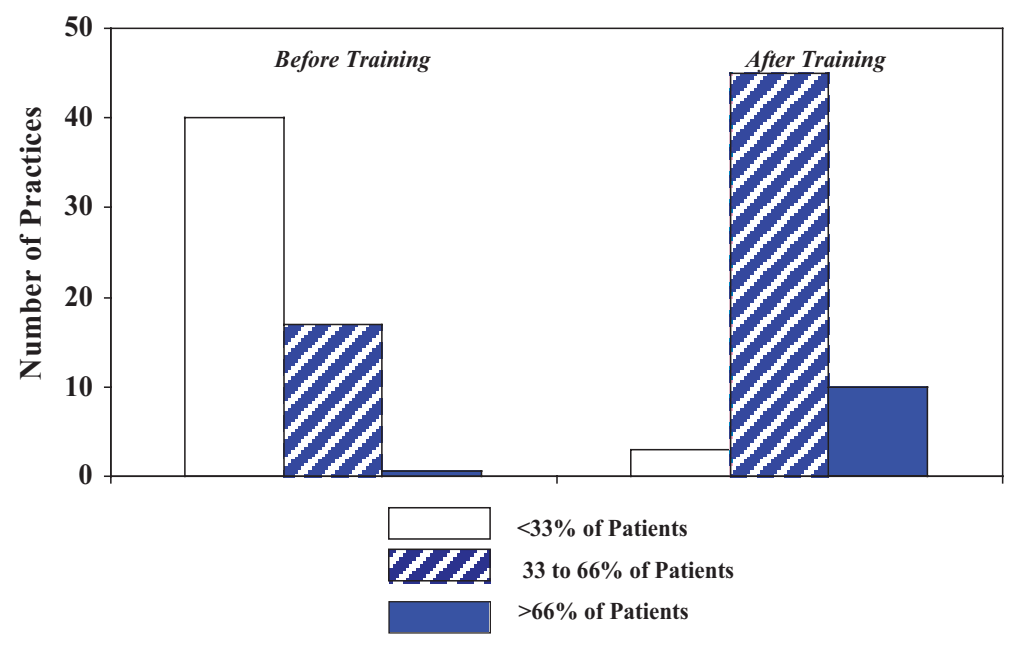


the Colorado Asthma Toolkit Program by providing a training arm that directly addressed the organization of asthma case within each practice. A total of 42 pediatric practices representing $638 \mathrm{pa}-$ tients willing to be interviewed were randomly assigned to (1) usual care; (2) peer-lead education in which one physician from each practice site was trained in evidence-based guidelines care and encouraged to share that information with peer clinicians; or (3) a planned care intervention that provided a comprehensive approach focused on changing the way the practice delivered asthma care, including standardizing visits and educating families to increase treatment adherence. Relative to the usual care group, patients of physicians in the peer-education group had fewer oral steroid bursts. Those in the planned care group also had greater treatment adherence and fewer oral steroid bursts and symptom days. ${ }^{27,28}$ Another study group trained one physician and nurse from each of 24 primary care practices to utilize the Asthma APGAR, a tool that surveys patients about symptoms and adherence and provides an asthma management flow sheet for providers. Chart reviews after training showed an increase in charting of asthma-related activities, assessment of inhaler technique, and prescribing of daily controller medication. ${ }^{8}$ In contrast to the Colorado Asthma Toolkit Program, none of these studies provided in-practice coaching that included the entire practice staff, and most focused on urban populations.

\section{Conclusion}

Patients living in rural areas often are less likely to have health insurance ${ }^{29}$ or to have access to health care clinicians able to provide guidelines-consistent care. ${ }^{16}$ Consequently, asthma is underdiagnosed and undertreated in rural areas ${ }^{29}$ despite higher rates of asthma hospitalization. ${ }^{30}$ Few programs have emerged to improve clinician skills for managing asthma in rural areas. The Colorado Asthma Toolkit Program provides one approach to improving health care for rural patients by coaching health care practices and clinicians to follow evidence-based asthma guidelines. The program incorporates in-practice coaching and training of caregiver teams that includes assessment and treatment of asthma. Further, coaching includes emphasis on patient education and adherence support, an element of particular importance given high rates of nonadherence in the face of decreasing willingness of primary care physicians to include asthma education during office visits. ${ }^{31}$

We thank Lori Jarrell (Toolkit trainer), and Christin Sutter and Susan Gale (High Plains Research Network Community Liaisons) for their major contributions to the implementation and evaluation of this project.

\section{References}

1. Chapman K, Boulet K, Rea R, Franssen E. Suboptimal asthma control: prevalence, detection and consequences in general practice. Eur Respir J 2008; 31(2):229-31.

2. Rabe K, Adachi M, Lai C, et al. Worldwide severity and control of asthma in children and adults: the global asthma insights and reality surveys. J Allergy Clin Immunol 2004;114(1):40-7.

3. Carlton B, Lucas D, Ellis E, Conboy-Ellis K, Shoheiber O, Stempel D. The status of asthma control and asthma prescribing practices in the United States: results of a large prospective asthma control survey of primary care practices. J Asthma 2005; 42(7):529-35.

4. National Heart, Lung, and Blood Institute. Expert Panel Report 3. Guidelines for the diagnosis and management of asthma. Washington, D.C.: US Department of Health; 2007.

5. Bender B, Pedan A, Varasteh L. Adherence and persistence with fluticasone propionate/salmeterol combination therapy. J Allergy Clin Immunol 2006; 118:889-904.

6. Stempel D, Stoloff S. Adherence to asthma controller medication regimens. Respir Med 2005;99(10): 1263-7.

7. Cabana M, Slish K, Evans D, et al. Impact of physician asthma care education on patient outcomes. Pediatrics 2006; 117(6):2149-57.

8. Yawn B, Bertram S, Wollan P. Introduction of asthma APGAR tools improve asthma management in primary care practices. J Asthma Allergy 2008;1-10.

9. Cloutier M, Hall C, Wakefield D, Bailit H. Use of asthma guidelines by primary care providers to reduce hospitalizations and emergency department visits in poor, minority, urban children. J Pediatr 2005; 146(5):591-7.

10. Harvey G, Loftus-Hills A, Rycroft-Malone J. Getting evidence into practice: the role and function of facilitation. J Adv Nurs 2002;37(6):577-88.

11. Goodwin M, Zyzanski S, Zronek S, et al. A clinical trial of tailored office system for preventive service delivery. The Study to Enhance Prevention by Understanding Practice (STEP-UP). Am J Prev Med 2001;21(1):20-8.

12. Margolis P, Lannon C, Stuart J, Fried B, KeyesElstein L, Moore DJ. Practice based education to 
improve delivery systems for prevention in primary care: randomised trial. BMJ 2004;328(7436):388.

13. Stange K, Goodwin M, Zyzanski S, Dietrich A. Sustainability of a practice-individualized preventive service delivery intervention. Am J Prev Med 2003; 25(4):296-300.

14. Hogg W, Baskerville N, Nykiforuk C, Mallen D. Improved preventive care in family practices with outreach facilitation: understanding success and failure. J Health Serv Res Policy 2002;7:195-201.

15. Ruhe M, Weyer S, Zronek S, Wilkinson P, Stange K. Facilitating practice change: Lessons from the STEP-UP clinical trial. Prev Med 2005;40(6):729-34.

16. Valet R, Perry T, Hartert T. Rural health disparities in asthma care and outcomes. J Allergy Clin Immunol 2009;123(6):1220-5.

17. Schatz M, Mosen D, Kosinski M, et al. Predictors of asthma control in a random sample of asthmatic patients. J Asthma 2007;44(4):341-5.

18. Stingone J, Claudio L. Disparities in the use of urgent health care services among asthmatic children. Ann Allergy Asthma Immunol 2006;27(2):244-50.

19. US Department of Health and Human Services, National Heart Lung and Blood Institute. Guidelines for the diagnosis and management of asthma (EPR-3). Available at: http://www.nhlbi.nih.gov/ guidelines/asthma/. Accessed March 19, 2011.

20. National Jewish Health. Print and multimedia materials. Available at: http://www.nationaljewish.org/ education/patient/print-multimedia/index.aspx. Accessed March 19, 2011.

21. Bender B, Apter A, Bogen D, et al. Controlled test of a iterative voice response intervention to improve adherence to controller medications in adults with asthma. J Am Board Fam Med 2010;23:159-65.

22. Sullivan S, Buxton M, Andersson L, et al. Costeffectiveness analysis of early intervention with budesonide in mild persistent asthma. J Allergy Clin Immunol 2003;112(6):1229-336.

23. Adams R, Fuhlbrigge A, Finkelstein J, et al. Impact of inhaled antiinflammatory therapy on hospitalization and emergency department visits for children and asthma. Pediatrics 2001;107(4):706-11.

24. Zemek RL, Bhogal SK, Ducharme FM. Systematic review of randomized controlled trials examining written action plans in children: what is the plan? Arch Pediatr Adolesc Med 2008;162(2): 157-63.

25. Colorado Asthma Surveillance Report. Colorado Department of Public Health and Environment, 2008. www.cdphe.state.co.us/ps/asthma/asthmasurveillancereport.pdf.

26. Brown R, Bratton S, Cabana M, Kaciroti N, Clark N. Physician asthma education program improves outcomes for children of low-income families. Chest 2004;126(2):369-74.

27. Lozano P, Finkelstein J, Carey V, et al. A multisite randomized trial of the effects of physician education and organizational change in chronic-asthma care: health outcomes of the Pediatric Asthma Care Patient Outcomes Research Team II Study. Arch Pediatr Adolesc Med 2004;158(9):875-83.

28. Sullivan S, Lee T, Blough D, et al. A multisite randomized trial of the effects of physician education and organization change in chronic asthma care: cost-effectiveness analysis of the Pediatric Asthma Care Patient Outcomes Research Team II (PACPORT II). Arch Pediatr Adolesc Med 2005;159(5): 428-34.

29. Ownby D. Asthma in rural America. Ann Allergy Asthma Immunol 2005;95(5 Suppl 1):S17-S22.

30. Knudson A, Casey M, Burlew M, Davidson G. Disparities in pediatric asthma hospitalizations. J Public Health Manag Pract 2009;15(3):232-7.

31. Hersh A, Orrell-Valente J, Maselli J, Olson L, Cabana M. Decreasing frequency of asthma education in primary care. J Asthma 2010;47:21-5. 